of this kind it should be remembered that the number of eggs hatched is of much greater importance than the number failing to hatch. With these results, then, it is evident that lime-sulphur, even too strong for use on foliage and fruit is, at best, an uncertain ovicide, its effectiveness of doubtful value economically.

\title{
WOOLLY APHID MIGRATION FROM ELM TO MOUNTAIN ASH $^{1}$
}

\section{Schizoneura lanigera (americana)}

\section{By Edith M. PAtch}

In the vicinity of Orono, the woolly aphid of the apple, Schizoneura lanigera, was abundant during the late summer and autumn of 1911 upon water shoots of certain apple trees; and upon trunk and branches of native mountain ash, Pyrus (Sorbus) americana; cultivated ornamental species of mountain ash, Pyrus sitchensis and others; and native and cultivated species of hawthorn, Cratcegus. Some of each of these trees were located with the view of studying the overwintering forms of this aphid, some of which, according to all published accounts, migrate up from the base of the tree in the spring to tender and susceptible places on the bark where they establish bark feeding colonies. No such occurrence, however, took place here the spring of 1912. The identical trees which were heavily infested with woolly aphid last fall were free from infestation this spring until late in June and then the infestation did not come from root aphids. Whether lanigera ever overwinters on the apple in this climate one season's observations are of course insufficient to ascertain. I had heretofore taken it for granted that it would do so and this point has not been previously investigated in this locality. Testimony as to this habit is desirable from other northern states and I shall plan to continue observations here for some years to come. It should be stated that these notes concern the trunk, branches and water shoots only; no roots being examined. If, however, root forms were present they and their progeny certainly remained buried this spring, as daily observations of selected trees were made. It seems not improbable that the hard packed condition of the clay soil in this immediate vicinity may be partly responsible for this circumstance. The fall migrants of this colony were mature and taking flight September 20-23.

1 Papers from the Maine Agricultural Experiment Station: Entomology No. 59. 
Through the kindness of several southern entomologists, elm leaf curl in considerable abundance with winged forms ready for migration was secured in May. These migrants as previously explained (Science, Vol. 36, pp. 30-31) were caged over apple seedlings greenhouse-grown for the purpose, the seeds having been planted in December 1911 and January 1912. A few very successful colonies of woolly aphids were thus established on apple seedlings by the progeny of the elm migrants, the earliest of which was one started by migrants received May 12 which is still flourishing, even in indoor conditions, at the time this paper goes to press.

Encouraged by the successful indoor tests, ${ }^{1}$ outdoor tests under more favorable conditions were made when the winged forms appeared in this vicinity.

Water shoots had been allowed to grow about the base of a mountain ash, Pyrus sp. on the campus and up to June 21 this tree and the shoots were free from woolly colonies. As the migrants are much more docile about sundown than earlier in the day, I placed several hundred elm migrants at the base of the water shooots, about $7 \mathrm{p}$. m. on June 21 . They moved about a little, most of them creeping to the ventral side of a leaf and remaining there; and during the night producing nymphs which sought the leaf axils of the water shoots so that by the afternoon of June 22 the tiny nymphs had already fed enough and secreted enough white wax to give the typical "woolly" appearance to the colonies. These and their progeny thrived on the mountain ash in a perfectly normal way for the woolly aphid of the apple.

Similar successful results were obtained by evening "plantings" of elm migrants upon uninfested water shoots of apple on June 24.

By this time the elm curl migrants were settling of their own accord on leaves of both mountain ash and apple and by June 28 colonies of

1 A very high percent of the indoor attempts to establish colonies upon apple seedlings, both with the material from the south and with Maine collections were unsuccessful. The reasons for the failures I do not know. The seedlings were grown from seeds removed from apples on the Maine market and it is possible that many of these plants were varieties not susceptible to attack. Though healthy, the seedlings were rather a scrubby lot, having received no fertilizer on the theory that "neglected orchards suffer worst from attacks of woolly aphids." The later outdoor experiments showed that the most vigorously growing water shoots of apple and mountain ash (Pyrus) were most readily accepted, which would indicate that if the seedlings had been forced as they are in the nursery they might have been better bait. I think, too, that freshly moulted migrants are often too restless and instinctively impelled to flight and dispersal to take kindly to confinement. Whatever the trouble, I have often had cause to recall Riley's remark on this species,- "There is much greater difficulty in fully tracing the life-history of one of these small creatures than might be supposed. They languish in confinement and ill bear handling." 


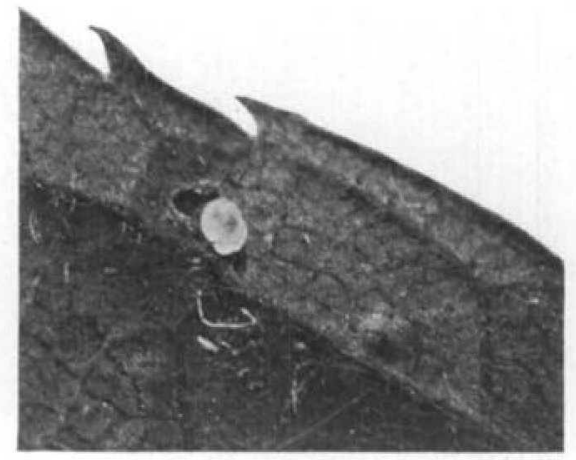

1. Metellus rubi, egg blister, one opened to show the egg and the one at the right intact.

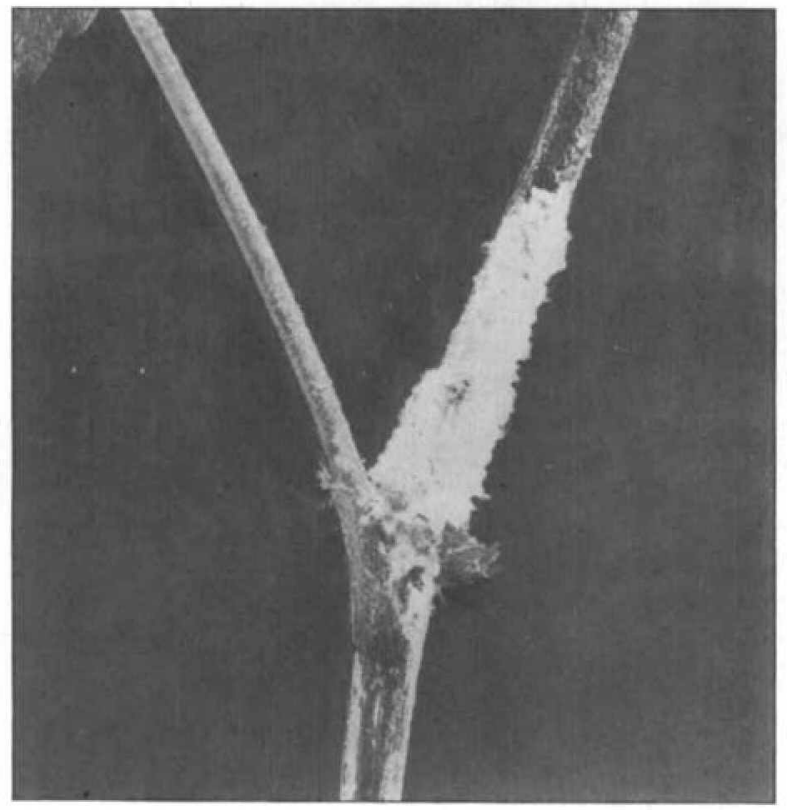

2. Nymphs of the Woolly Aphid, Schizoneura lanigera (americana), on mountain ash, Pyrus americana,-the immediate progeny of migrants from elm leaf curl. Photographed at Orono, June 28, 1912. 
nymphs of woolly aphid were easily found on both these summer hosts. That these were the progeny of the elm leaf migrants there was evidence enough. One native mountain ash, Pyrus americana, will serve for an illustration. The main trunk of this tree was dead nearly to the ground, but twelve vigorous shoots had grown up measuring about five feet each. On June 28 this mountain ash had about 150 woolly masses of nymphs grouped on the stem at the leaf axils. These nymphs ranged from very tiny ones to half grown insects, none being mature at that date. One such woolly mass contained 155 individuals of various sizes. (See plate 10, figure 2.) On the ventral surfaces of the leaves of this mountain ash were stationed many elm leaf migrants producing there their broods of nymphs which could be seen, with the hand lens, to be augmenting the woolly masses on the stem. Collections of these migrants thus stationed were made as follows:-July 2, 88 migrants; July 3, 211 migrants; July 5, 92 migrants; July 8, 54 migrants; July 9, 80 migrants; July 10, 33 migrants; July 11, 14 migrants; July 12, 3 migrants. Only living individuals were collected, dead ones being brushed off and discarded in the counts. Microscopic examination showed them to be identical with winged forms collected in elm leaf curls. Two large elm trees with leaves well stocked with this species stood about a rod distant.

Correlated with the appearance of the stem colonies of woolly aphides on mountain ash (Pyrus sp.) and water shoots of apple which were definitely ascertained to be the progeny of elm leaf migrants, were woolly bark feeding colonies on the trunks and branches of the elm, Ulmus americana. These were mostly about pruning wounds or protected under the bark, the latter colonies often not visible except on scaling back the bark. That these bark colonies on the elm are also the progeny of elm leaf migrants I have no doubt; but as the chief point of interest this year was centered in watching the elm leaf-apple situation no real attempt was made to get at the elm leafelm bark situation by catching the bark colonies in the process of making. This should not be especially difficult to do and is listed among the plans for 1913. In this connection it should be remembered that Riley's classic work on this species gives a continuous cycle for the elm in which he states of the fourth generation (progeny of the winged generation developing in the leaves): "They are, however, able to sustain themselves on the tender bark of twigs alone, and may be found nearly fully-grown, there exposed to view and enveloped in the white cottony matter, which brushes off at the slightest touch."

What influences the destination of the elm-leaf migrants and what determines their choice of the summer food plant for their progeny is not known. That they readily accept elm bark under some conditions 
Riley's account testifies. That they migrate to water shoots of apple; to mountain ash (Pyrus species) and to hawthorns (Cratcegus species), there producing progeny known as the woolly aphid of the apple, I have had definite and repeated proof.

The woolly colonies (mostly hidden under rough bark) are this season more abundant upon the elm than upon the apple in this vicinity, comparatively few of the apples being colonized, the mountain ash being here conspicuously a favorite summer host for Schizoneura lanigera (americana).

A bulletin of the Maine Agricultural Experiment Station (No. 203) now in press treats of certain phases of this problem not touched upon in the present paper.

An especial study of the antennal variation of this species is under way, it being purposed to tabulate at least 1000 antennæx, with camera lucida sketches of the more significant variations. The two extremes of the variable series show a difference wide enough to "separate lanigera from americana on good antennal characters." However, a large series renders a separation on this basis impossible. Although the discussion of this important point is postponed until the requisite data are tabulated, it may be of interest in this connection to state that a single collection of elm leaf migrants made at Orono show a range of from 19 to 32 annular sensoria on antennal joint III; 4 to 9 on IV, 2 to 10 on V: 0 to 2 on VI.

White Grubs (Lachnosterna species). These common pests were excessively abundant the past summer, at least in Albany, Columbia and Rensselaer counties, $N$. $Y$, they being so very numerous in many fields as to destroy practically all the grass roots so that large patches were badly pulled by the horse rake. Strawberry beds and corn were also seriously affected, especially when planted on sod. The greatest damage was confined to old seedings or meadows and usually to moister portions of the fields. These grubs were probably a little over a year old and may be those of Lachnosterna fusca Froh., since this was one of the species abundant in May and June 1911. In addition to these two, L. grandis Sm., L. hirticula Knoch and $L$. hirsula Knoch were observed in abundance last year. Several species of June beetles were numerous last spring so that a continusnce of the above noted depredations, probably on a more limited scale, may be expected in 1913.

E. P. Felt. 